\title{
Author Correction: Tissue repair and regeneration with endogenous stem cells
}

Huimin Xia, Xin Li, Weiwei Gao, Xin Fu, Ronnie H. Fang, Liangfang Zhang and Kang Zhang

Nature Reviews Materials (2018) https://doi.org/10.1038/s41578-018-0027-6

Published online 19 June 2018

This article was originally published with an incorrect affiliation 1 . The correct affiliation 1 is: Department of Pediatric Surgery and Center for Genetic Diagnosis, Guangzhou Women and Children's Medical Center, Guangzhou Medical University, Guangzhou 510623, Guangdong, China

https://doi.org/10.1038/s41578-018-0041-8 I Published online 27 July 2018 